Serial No. 592.--Sample of canned pineapples, bought of Mr. Brown, Fifth avenue, August 4, 1890. Labeled: Pineapples, First Quality. Packed by Martin Wagner \& Co., Baltimore, Md.

Tin dioxide. $0.0098 \%$

Grains per pound . . . . . . . . . . . . . . . . . . 0.686

Equivalent to stannous chloride . . . . . . . . . . . 0.864

Mininum doses . . . . . . . . . . . . . . . . . . . . . . . . 13.6

Maximum doses .......................... 1.

Can eroded.

Serial No.593.- Sample of canned pineapples, bought of $\mathrm{Mr}$. Brown, Fifth avenue, August 4, 1890. Labeled: Florida Pineapple, Oval Brand. Extra Quality. A. Booth Packing Co., Baltimore, Ma.

'Tin dioxide . . . . . . . . . . . . . . . . . . . $0.0158 \%$

Grains per pound .......................... 1.11

Equivalent to stannous chloride.............. 1.4

Mininum doses . . . . . . . . . . . . . . . . . . . . . . . 22.4

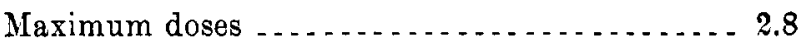

Can eroded.

\title{
A NEW FORM OF VOLTAMETER.
}

By Dr. G. C. Caldwell.

In the recent development of electrolytic analysis it has come to be shown that a more careful adjustment of the strength of the current is essential, and that for much of the work very weak currents, evolving even as little as 0.1 or 0.2 c.c. of oxy-hydrogen gas per minute must be used for the best results; and it is not often, for any practicable determinations, that a current yielding over 10 c.c. per minute is required. 
'Therefore a voltameter that will readily show in its upper pirt tenths of a cubic centimeter is essential, and with a total capacity of 10 c.c. in its measuring tube is quite large enough, while in the measurement of the stronger currents the accurate reading to tenths is not important.

Classen's voltameter is familiar to those who make much use of electrolytic analysis. With its capacity of 30 c.c. it is unnecessarily cumbersome; and it is practically impossible to prevent slow leakage of the acid liquid when the rubber tube connects with the glass tubes. Other voltameters figured or described in the apparatus lists are now no more convenient.

For my own use I have devised the arrangement, made for me by Greiner, shown in the figure. It needs little explanation.

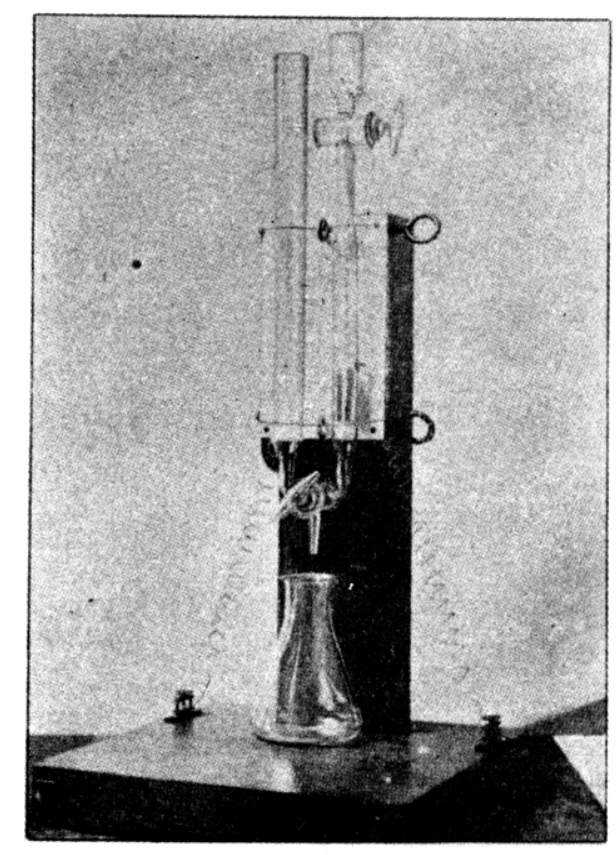

The lower stop cock is three-way, so that the two tubes can be connected with one another, or each or both with the outflow jet, 
at pleasure. The distance from the lower to the upper stop cock is $21 \mathrm{~cm}$., the diameter of the wider part of the graduated tube about $16 \mathrm{~mm}$., the length of the narrow part, especially for measuring tenths, is $4 \mathrm{~cm}$, and, as shown, this holds about 2 c.c.

The instrument is conveniently supported on a wooden stand, and lield in place by two pieces of $\mathrm{D}$ violin strings, each piece having a loop at one end that passes over the head of a small screw in the side of the post, then through a small screw eye in front, then through a small hole in the shank of a larger screw eye in the other side of the post; by holding the end of the string cautiously near the lamp flame, it will swell sufficiently so that it cannot slip out through the hole again; then by turning the screw eye, a very little tightening of the string holds the instrument firmly in place.

Ordinary binding posts on the base of the stand can, of course, be used instead of the screw clamps; but with the wires from the electrodes soldered to these clamps, they serve the purpose well.

The acid electrolyte will leak even around a vaselined glass stopper, in time. But it is not at all essential to have an outflow at the bottom, especially if the reservoir tube is made somewhat wider than the other. The diminution of the volume of the gas under the pressure of the longer column of liquid in the reservoir tube is too small to be of account in this work. Even in my own instrument, with a reservoir tube only $17 \mathrm{~mm}$. wide, when 2 c.c. have been collected, the change in volume by allowing the excess of liquid in the reservoir tube to flow out is inappreciable; when the level in the graduated tube has fallen to the mark for 9 c.c. and the reservoir tube is full to the top, the increase in rolume is but 0.2 c.c. when both levels are brought to the same height. Without the three-way, outflow stop cock the instrument would, of course, be much cheaper and practically quite as serviceable.

CorNell LNIVERSity, July, 1891. 